\title{
Rare Thoracolumbar Facet Synovial Cyst Presenting as Paraparesis
}

\author{
Anshul Dahuja', Gitanshu Dahuja', Rashmeet Kaur ${ }^{2}$ \\ Departments of ${ }^{1}$ Orthopedics, ${ }^{2}$ Radiodiagnosis, GGS Medical College Faridkot, Faridkot, India
}

Spinal cord compressing syndrome due to synovial cyst (SC) of the thoracolumbar spine is a rare clinical condition. In this report we aim to heighten awareness of the thoracolumbar facet synovial cyst as a possible cause of thoracic myelopathy. The SC was removed thoroughly by laminectomy. The patient had an excellent recovery. The etiological and therapeutic aspects are discussed.

Key Words: Laminectomy $\cdot$ Myelopathy $\cdot$ Synovial cyst

\section{INTRODUCTION}

Intraspinal synovial cysts are reported with increasing frequency in the literature but continue to be an uncommon cause of radicular pain ${ }^{9}$. These cysts have intraspinal and extradural location and originate from the facet capsules caused by degeneration of the facet joints, being therefore known as synovial, juxtafacet, ganglion, or ligamentum flavum cysts ${ }^{3)}$. Incidentally, can be diagnosed during pain when the investigations are located in the spine and/or due to myeloradicular symptoms; now they are more easily diagnosed through magnetic resonance imaging $(\mathrm{MRI})^{1}$. This enables accurate preoperative planning and avoidance of therapeutic pitfalls. The SC of the thoracolumbar spine is infrequent and the world literature shows a shortage of documented cases. This fact collaborates with the aim of this study, presentation of a case of SC in a middle aged patient, occurring in the thoracolumbar spine and developing progressively compressive symptoms and successfully treated by surgical excision.

\section{CASE REPORT}

A 34 years-old lady was admitted with a chief complain of weakness in the left lower limb which had started six months

- Received: March 25, 2015 - Revised: August 8, 2015

- Accepted: August 8, 2015

Corresponding Author: Anshul Dahuja, MD, MS, Mch

Departments of Orthopedics, Surgery, GGS Medical Collge Faridkot,

Pin 151203, Punjab, India

Tel: +07307420300, Fax: + 163925232

E-mail: anshuldahuja@gmail.com

凤This is an Open Access article distributed under the terms of the Creative Commons Attribution Non-Commercial License (http://creativecommons.org/ licenses/by-nc/3.0/) which permits unrestricted non-commercial use, distribution, and reproduction in any medium, provided the original work is properly cited. earlier. In the beginning she felt an intermittent weakness, mainly in the left, that interfered in the daily activities. The weakness was progressive, followed by cramps, tingling and interfering in the gait. No alteration of anal and vesical sphincter function. The general examination showed good overall state. The patient was alert, lucid and guided, but with depressed humor. Vital signs were normal. The cardio-respira- tory system and the abdomen did not show any alteration during examination. Neurological examination showed: asymmetrical paraparesis $(\mathrm{L}>\mathrm{R})$; moderate hypertonia $(\mathrm{L}>\mathrm{R})$; increased deep tendon reflexes in the lower limbs. Bilateral Babinski sign showed more evident on left side. Decreased kineticpostural sensibility were detected in the lower limbs; no involvement of cranial nerves.

Laboratory tests (complete blood count, biochemical study, electrolytes, urine summary) were normal; MRI of the thoracolumbar spine showed image of cystic aspect of extradural location in T12-L1, hypointense on the T1-weighted sequence and hyperintense on T2-weighted sequence (Fig. 1). Surgical treatment was indicated and a laminectomy accomplished at T12-L1 level, where an extradural cystic tumor was found with posterolateral left location adherent at T12-L1 level. Axial com-
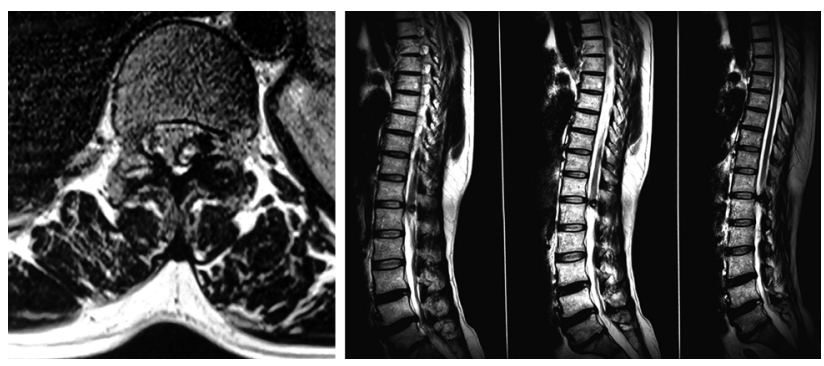

Fig. 1. Axial and sagittal MRI sequences showing well defined intraspinal extradural hyperintense lesion with hypointense rim in relation to left facet joint indenting on thecal sac at the dorsolumbar level. 


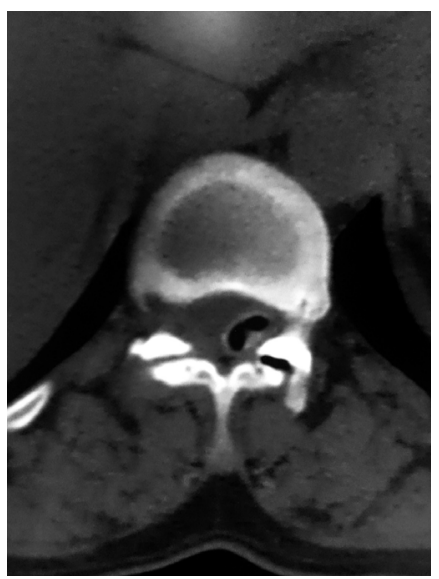

Fig. 2. Axial CT scan showing pathognomic finding of degenerative air locule in left facet cyst and joint.

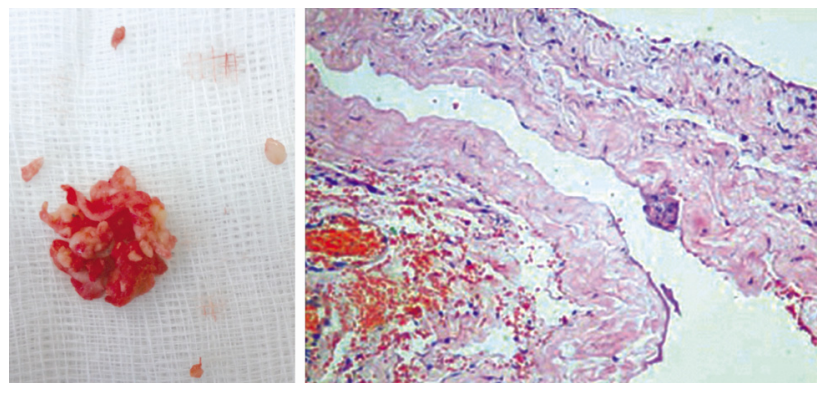

Fig. 3. Gross and HPE of the specimen of the cyst showing focally detectable synovial cells covering a stroma with vascular granulation tissue.

puted tomography (CT) scan showed at same level showed degenerative changes in left facet joint and adjacent cyst (Fig. 2).

The cyst was removed as shown in Fig. 3, the capsule was completely removed and sent for histopathology study which showed cystic formation with thin fibrous walls covered by pavimentous cells in the internal surface; presence of thin perivascular inflammatory infiltrate, compatible with synovial cyst (Fig. 3). Postoperatively the patient showed signs of clinical improvement in terms of decreased pain and paraesthesias. One month later the patient started walking without any assistance.

\section{DISCUSSION}

Spinal SC was initially described in $1974^{8)}$. In that study the authors presented a case of SC of the cervical spine operated with success and confirmed by histopathological study. Other authors have reported the presence of this pathology in different locations of the spine. The largest incidence was in the lumbar followed by cervical and less frequently in the thoracic spine. Most of the studied cases prevail in the male sex ${ }^{3)}$. The pathological substratum responsible for the development of the spinal SC includes the degeneration and arthrosis of the articulate facets, causing secondary lesion of the joint capsule and formation of hernia of the synovial membrane.

The presence of myxoid degeneration increases the production of hyaluronic acid with proliferation of mesenchymal cells contributing for the emergence and size of the cysts ${ }^{10}$. Present clinical observation and experimental date, suggest that the mechanical pressure in the articular facet induces the appearance of a cascade of events as follows: upregulations and release of angiopoietin-1, interleukins- 1 and 6, plateletderived growth factor, basic fibroblast growth factor, vascular endothelial growth factor and substance P liberation, resulting in synovial hyperplasia, neovascularization and exudation of fluid, culminating with the formation of the cysts ${ }^{5}$. This process could be reversible because the synovial proliferation can decrease on withdrawal of mechanical stress, what in some cases promotes the spontaneous reduction of the cysts ${ }^{5}$.

The spondylolisthesis and the trauma can also be responsible for the emergence of these cysts. The content can be mucinous, with proteinaceous material and sometimes gaseous. They can present calcification focus or old intracystic hemorrhagic signs.

Bleeding can occur by traumatism of the cyst wall due to the abundance in veined structures.

The preferential location of SC is in the great mobility lumbar spine segments followed by the cervical and less frequently in the thoracic spine. A literature review shows the existence of few told cases in the thoracic location. In 2004 CohenGodol et al. ${ }^{4)}$, published 9 cases of SC of lower thoracic spine in a total of 16,000 studied and submitted to the decompressive surgery of the spine due degenerative causes among others. And this is postulated that as T10-L1 represents the transitional zone between relatively immobile thoracic spine and highly mobile lumbar segments so among documented thoracic cysts majority fall in this transitional zone. The above mentioned cases correspond to $0.06 \%$ of the total and some literature refer that in the period from 1987 to 2004 only 10 cases have been described reaffirming the low incidence of this pathology. With the exception of a case described by Lynn et al. ${ }^{12)}$ in 2000, of a patient with 24 years-old, the average incidence of this pathology is related to patients of age above 70 years-old.

These cysts may extend into the neural recess and cause radiculopathy ${ }^{11)}$. Clinical presentation may include neurogenic claudication resulting from spinal cord compression by a large cyst $^{6}$. Symptoms are usually ipsilateral to the side of the cyst; occasionally, larger cysts can also cause contralateral radicular symptoms ${ }^{13)}$. MRI is the investigation of choice in these patients. A lumbar facet joint synovial cyst usually appears as a well demarcated epidural mass with contents isointense or 
hyperintense to cerebrospinal fluid on T1- and T2-weighted fast spin-echo images ${ }^{14)}$. The slight hyperintensity sometimes seen has been attributed to various causes; one possible explanation is that small amounts of paramagnetic blood breakdown products present in the cyst fluid may be responsible ${ }^{7,8)}$. Occasionally, the synovial cysts may appear hypointense on both T1- and T2-weighted images, which is usually caused by solid calcification in the cyst. MRI may occasionally show signal void due to vacuum phenomenon, and in these cases CT is more helpful in revealing the intracystic air ${ }^{1)}$. The rim of the cyst shows high signal intensity on T1- weighted images except when peripheral calcification or hemosiderin deposition is present ${ }^{6,11)}$. In addition, the cyst rim may show enhancement after the administration of gadolinium ${ }^{11)}$. Tillich et al. showed that a communication is always present between the synovial cyst and the facet joint at surgery, but this is seen in only a minority of cases on MRI, which is probably because of the relatively small size of the communication ${ }^{14)}$. The communication enables the filling and emptying of the cyst, which is dependent on the mechanical stresses and postural changes of the spine ${ }^{2,3)}$. This explains the size variations of the cysts on follow-up imaging in some cases ${ }^{1-3)}$. Symptomatic facet joint cysts are usually surgically resected ${ }^{13)}$. Our patient underwent L3-L4 medial facetectomy and resection of the cyst. The patient reported significant improvement in the symptoms at out patient review.

\section{CONCLUSION}

Although an uncommon condition, it remains the cause of back pain and sciatica in a significant minority of patients and should be readily diagnosed on MR imaging. Surgical removal of synovial cyst is associated with favourable outcome.

\section{REFERENCES}

1. Apostolaki E, Davies AM, Evans N, Cassar-Pullicino VN: MR imaging of lumbar facet joint synovial cysts. Eur Radiol 10:615623, 2000

2. Bjorkengren AG, Kurz LT, Resnick D, Sartoris DJ, Garfin SR: Symptomatic intraspinal synovial cysts: opacification and treatment by percutaneous injection. Am J Roentgenol 149:105-107, 1987

3. Bozzao A, Floris R, Fraioli C, Ticca L, Simonetti G: "Relapsingremitting" bilateral synovial cysts of the lumbar spine: a case report. Neuroradiology 43:1076-1078, 2001

4. Cohen-Gadol AA, White JB, Lynch JJ, Miller GM, Krauss WE: Synovial cysts of the thoracic spine. J Neurosurg Spine 1:52-57, 2004

5. Colen CB, Rengachary S: Spontaneous resolution of cervical synovial cyst. Case illustration. J Neurosurg Spine 4:186, 2006

6. Howington JU, Connolly ES, Voorhies RM: Intraspinal synovial cysts: 10-year experience at the Ochsner Clinic. J Neurosurg 91:193-199, 1999

7. Jackson DE, Atlas SW, Mani JR, Norman D: Intraspinal synovial cysts: MR imaging. Radiology 170:527-530, 1989

8. Kao CC, Winkler SS, Turner JH: Synovial cyst of spinal facet. Case report. J Neurosurg 41:372-376, 1974

9. Kouyialis AT, Boviatsis EJ, Korfias S, Sakas DE: Lumbar synovial cyst as a cause of low back pain and acute radiculopathy: a case report. South Med J 98:223-225, 2005

10. Lima R, Spagamalo E, Johnston E: Quistes sinoviales espinales sintomáticos. Rev Hosp Maciel 4:10-15, 1999

11. Liu SS, Williams KD, Drayer BP, Spetzler RF, Sonntag VK: Synovial cysts of the lumbosacral spine: diagnosis by MR imaging. Am J Roentgenol 154:163-166, 1990

12. Lynn B, Watkins RG, Watkins RG IV, Williams LA: Acute traumatic myelopathy secondary to a thoracic cyst in a professional football player. Spine (Phila Pa 1976) 25:1593-1595, 2000

13. Lyons MK, Atkinson JL, Wharen RE, Deen HG, Zimmerman RS, Lemens SM: Surgical evaluation and management of lumbar synovial cysts: the Mayo Clinic experience. J Neurosurg 93:5357, 2000

14. Tillich M, Trummer M, Lindbichler F, Flaschka G: Symptomatic intraspinal synovial cysts of the lumbar spine: correlation of MR and surgical findings. Neuroradiology 43:1070-1075, 2001 